\title{
SUB-TEMPERATE BASAL SLIDING
}

\author{
By A. C. FOWLER
}

(Mathematical Institute, 24-29 St Giles', Oxford OX1 3LB, England)

ABSTRACT. Recent observations of glacier sliding at temperatures below the melting point are discussed. It is pointed out that these observations can be simply explained by including solid friction in the sliding law. Furthermore, we re-emphasize the point that such sub-temperate sliding has an important effect on the basal boundary conditions which should be applied in model studies of ice sheets and
glaciers.

RÉsumÉ. Dérapage sub-tempéré. On examine des observations récentes de dérapage à des températures inférieures à la température de fusion. On montre que ces observations peuvent être expliquées simplement en incorporant un frottement solide à la loi de glissement. En outre on souligne a nouveau le fait que ce glissement

It has recently been suggested by Shreve (1984) that glaciers may slide when the basal temperature is below the freezing point, and two independent sets of observations by B. Hallet and $\mathbf{K}$. Echelmeyer were reported at the Interlaken Conference on the Hydraulics of Glaciers (September 1985), which confirm this opinion. Echelmeyer reported small $\left(\sim 0.2 \mathrm{~m} \mathrm{a}^{-1}\right)$ but measurable sliding rates at a temperature of $-4.6^{\circ} \mathrm{C}$; Hallet reported significant sliding at about $-1{ }^{\circ} \mathrm{C}$ in ventilated cavities; the motion was of stick-slip type.

These observations suggest that the sliding law relating basal velocity and basal stress should depend also on temperature, thus

$$
u=\mathrm{F}(\tau, T)
$$

where $u$ is velocity, $\tau$ is stress, and $T$ is temperature. It has been pointed out (e.g. Fowler, 1979) that a temperaturedependent sliding law is to be expected on simple physical grounds, since when $T$ is, say, $10^{-2}{ }^{\circ} \mathrm{C}$ below $T_{\mathrm{M}}$ (melting temperature), pressure variations of $O(1 \mathrm{bar})$ at the interface (due to viscous flow round protuberances) will enable part of the basal ice to reach $T_{M}$ at the bed and thus lubricate the interface. Thus, one would expect a partly lubricated and partly frozen bed, and hence (on average) a non-zero basal velocity less than the full (temperate) value

$$
u=F_{\mathrm{M}}(\tau)=\mathrm{F}\left(\tau, T_{\mathrm{M}}\right) .
$$

The range over which one might expect a non-zero from this process would be $0.1 \mathrm{deg}$ if one supposes possible pressure variations over smooth beds of $\leqslant 10$ bar. Thus, neither Hallet's nor Echelmeyer's observations can be explained in this way. Also, Shreve's theory, based on Gilpin's liquid-like layer, apparently cannot account for Hallet's observation.

A simple explanation of sub-temperate sliding follows from including the effects of solid friction. Solid ice at sub-freezing temperatures slides over an underlying substratum by mechanisms described by Barnes and others (1971). For sliding speeds characteristic of glaciers, their data (see their fig. 9) can be reasonably represented by the relation

$$
\tau_{\mathrm{f}}=N f(u) g(T)
$$

where $N$ is the normal pressure and $f$ is a function which sub-tempéré est une condition aux limites importante qui doit être prise en compte lorsque l'on modélise calottes et
glaciers.

ZUSAMMENFASSUNG. Untertemperiertes Gleiten am Untergrund. Neuere Beobachtungen zum Gletschergleiten bei Temperaturen unter dem Schmelzpunkt werden erörtert. Es stellt sich heraus, dass diese Beobachtungen einfach zu erklären sind, wenn Reibung zwischen festen Körpern in das Gleitgesetz eingeführt wird. Weiter wird erneut darauf hingewiesen, dass solches untertemperiertes Gleiten sich stark auf die Randbedingungen am Untergrund auswirkt, die in Modellstudien für Eisdecken und Gletscher anzuwenden
sind.

is monotone increasing for $u \leqslant 100 \mathrm{~m} \mathrm{a}^{-1}$, and approximately constant for $u$ above this (until $u \gtrsim 10^{3} \mathrm{~m} \mathrm{a}^{-1}$, when $f$ decreases due to lubrication by frictionally melted water) The function $g$ increases as $T$ decreases, and if $\max . f=1$, then $g(-0.5) \approx 0.2, \quad g(-6.0) \approx 0.7, \quad g(-12.0) \approx 0.9$, $g(-18.0) \approx 1.1$. A reasonable representation of the function $g$ is then

$$
g(T) \approx 0.28 \theta^{\frac{1}{2}}
$$

where

$$
\theta=T_{\mathrm{M}}-T
$$

is the sub-cooling. The function $f(u)$ seems approximately linear in $\ln u$ for $u_{0}<u<u_{\mathrm{m}}$, where $u_{\mathrm{o}}$ depends to some extent on temperature but may be taken as about $10^{-8} \mathrm{~m} \mathrm{~s}^{-1}$ $\approx 0.3 \mathrm{~m} \mathrm{a}^{-1}$, and $f\left(u_{\mathrm{o}}\right) \approx 0$. The upper limit $u_{\mathrm{m}}$ of this linear behaviour also depends on temperature, but is typically about $10^{-5} \mathrm{~m} \mathrm{~s}^{-1}$, i.e. $300 \mathrm{~m} \mathrm{a}^{-1}$. Then

$$
f(u) \approx \ln \left(u / u_{0}\right) / \ln \left(u_{m} / u_{0}\right) .
$$

In order to compute a sub-temperate sliding law, we normalize the variables. If $d$ is a local glacier or ice-sheet depth and $\alpha$ is the local surface slope, then we write

$$
\begin{aligned}
& \tau=\rho g d \alpha \tau^{*}, \\
& N=\rho g d N^{*}
\end{aligned}
$$

where $\rho$ is density and $g$ is gravity; if $d$ is actually the local depth, then $\tau^{*} \approx 1$, if the bed is sufficiently smooth on a large scale, and $N^{*} \approx 1$, if basal water is absent. More generally, $T^{*}, N^{*} \sim O(1)$.

In the absence of cavitation (and regelation), Fowler (1981) suggested a sliding law (without friction)

$$
T^{*}=R\left(u^{*} / \mu_{1}\right)^{1 / n}
$$

where $R \sim O(1), n$ is the exponent in Glen's law, and $\mu_{1}$ is a measure of the roughness of the bed. Here, the velocity
has been normalized as

$$
u=U u^{*},
$$

and for illustration we suppose $U \approx 100 \mathrm{~m}^{-1}$. Fowler (1981) showed that an applied stress at the bed appears additively 
in Equation (8); hence we would propose an approximate sub-temperate sliding law of the form

$$
\tau^{*} \approx R\left(u^{*} / \mu_{1}\right)^{1 / n}+N^{*} \theta^{* \frac{1}{2}}\left\{1+\delta \ln u^{*}\right\}
$$

where we have normalized the sub-cooling $\theta$ as

$$
\theta=(\Delta T) \theta^{*},
$$

and have chosen

$$
u_{0}=10^{-1} \mathrm{~m} \mathrm{a}^{-1}, u_{\mathrm{m}}=10^{3} \mathrm{~m} \mathrm{a}^{-1}, U=10^{2} \mathrm{~m} \mathrm{a}^{-1},
$$

and thus

$$
\delta=1 / \ln \left(U / u_{0}\right) \approx 0.14
$$

and

$$
\Delta T=\left[\frac{\alpha}{0.28} \frac{\ln \left(u_{\mathrm{m}} / u_{0}\right)}{\ln \left(U / u_{0}\right)}\right]^{2} \approx(4.76 \alpha)^{2} \mathrm{deg} .
$$

Thus for $\alpha=0.1, \Delta T \approx 0.22$ deg. $\Delta T$ measures the range of sub-cooling over which we expect sliding to be significant.

To elucidate the meaning of Equation (10), we consider $u^{*}$ at fixed $\tau^{*}$ and $N^{*}$ as a function of the dimensionless subcooling $\theta^{*}$. Then we take advantage of the smallness of $\delta$, to deduce

$$
u^{*} \approx \mu_{1}\left[\left(\tau^{*}-N^{*} \theta^{* \frac{1}{2}}\right) / R\right]^{n},
$$

for $\theta^{*}<\left(\tau^{*} / N^{*}\right)^{2}$. In the simplest case, where longitudinal stresses are negligible, then $\tau^{*}=N^{*}$, and Equation (15) implies that the sliding velocity is reduced from its fully temperate value by a factor $\left(1-\theta^{* \frac{1}{2}}\right)^{n}$.

Equation (15) ceases to be valid when $u^{*} \ll 1$, specifically when $u^{*} \sim \mathrm{e}^{-1 / \delta}$, i.e. when $u \sim u_{0}<1 \mathrm{~m} \mathrm{a}^{-1}$. We find that $u^{*}$ decreases to $u_{0} / U$ as $\theta^{*} \rightarrow \infty$. That is, $u \rightarrow u_{0}$. This result is due to the vanishing of the coefficient of friction at $u=u_{0}$. However, Barnes and others' (1971) results show a dependence of $u_{0}$ on $T$, such that $u_{0} \rightarrow 0$ as $T$ decreases. Thus, it is more realistic to suppose $u^{*} \rightarrow 0$ as $\theta^{*} \rightarrow \infty$, with $u \sim u_{0}$ for $\theta^{*}>\left(\tau^{*} / N^{*}\right)^{2} \approx 1$.

To summarize, we find significant sliding for $T_{\mathrm{M}}-T$ $>\Delta T$ given by Equation (14), and non-zero but very small sliding for $T_{\mathrm{M}}-T<\Delta T$. These results could be used to explain both Hallet's observations (e.g. if $\alpha=0.2$ ) and Echelmeyer's $\left(u<1 \mathrm{~m} \mathrm{a}^{-1}\right)$ at $\left.T \approx-5^{\circ} \mathrm{C}\right)$. It should be added, however, that the temperature range $\Delta T$ will be affected by deviations of the shear stress from Nye's formula $\tau=\rho g d \alpha$. Cavities will affect the form of Equation (10) but not the principal conclusions. However, the value of $\Delta T$ will be affected by the applicability of Barnes and others' result to the friction of ice over rough rocks. Thus, it is to be expected that the precise value of $\Delta T$ may vary from glacier to glacier but one would expect a discernible variation with surface slope. Also, the reasonably sharp distinction between significant (Hallet) sliding $\left(0<T_{\mathrm{M}}-T<\Delta T\right)$ and insignificant (Echelmeyer) sliding $\left(T_{\mathrm{M}}-T>\Delta T\right)$ is a robust conclusion from this analysis.

\section{IMPLICATIONS}

In modelling the flow of glaciers and ice sheets, one seeks a basal boundary condition on the velocity. We now take this to be of the form of Equation (1). The previous discussion suggests that an effectively useful approximation may be something like Equation (15) for $T_{M}-T<\Delta T$, and $u^{*} \approx 0$ for $T_{\mathrm{M}}-T>\Delta T$. Now, many glaciers experience ranges of $\mid T$ of $10-20 \mathrm{deg}$, and ice sheets experience variations of $50 \mathrm{deg}$. So our estimate of $\Delta T(0.2$ deg) appears small and one wonders how to incorporate this smallness of $\Delta T$ in an approximate manner. Even a larger effective $\Delta T$, e.g. 1 or $2 \mathrm{deg}$, will be small if temperature variations are important. It then makes sense to seek the appropriate expression of the temperature-dependent sliding law when $\Delta T \rightarrow 0$. Apparently, we should postulate

$$
\begin{array}{ll}
u=F_{\mathrm{M}}(\tau), & T=T_{\mathrm{M}}, \\
u=0, & T<T_{\mathrm{M}},
\end{array}
$$

for small $\Delta T$. However, such a law gives a discontinuous velocity when $T$ first equals $T_{\mathrm{M}}$ and hence infinite stresses and, in fact, requires an infinite force at the base. This unphysical result has been discussed by Hutter (1982). It can be alleviated to an extent by artificially making $u$ continuous but not differentiable when $T$ first equals $T_{\mathrm{M}}$. Then, one finds stress singularities, but not force singularities, at the cold-temperate transition (Hutter and Olunloyo, 1980, 1981). Clarke and others (1984) found no evidence for such a singularity on Trapridge Glacier.

Fowler (1979) and Fowler and Larson (1980) showed that if $u$ depends continuously on temperature as here, so that $u$ changes from zero to $F_{\mathrm{M}}(\tau)$ over a range $\Delta T$, then the limiting behaviour is not that of Equation (16), because the extent of the sub-temperate (i.e. $T_{\mathrm{M}}-\Delta T<T<T_{\mathrm{M}}$ ) region does not vanish in the limit $\Delta T \rightarrow 0$. The correct sequence of boundary conditions as $\Delta T \rightarrow 0$ is the following

$$
\left[T<T_{\mathrm{M}}\right] ; \quad u=0,-k \partial T / \partial y=G .
$$

Here, $G$ is the prescribed geothermal heat flux, $k$ is the thermal conductivity, and $y$ is vertical distance upwards. The sub-temperate region is described (in the limit $\Delta T \rightarrow 0$ ) as follows:

(b) $\left[0<u<F_{\mathrm{M}}(\tau)\right] ; \quad T=T_{\mathrm{M}},-k \partial T / \partial y=G+\tau u$.

This includes the viscous heat generated in the basal layer, which is all fed into the cold ice above. Thus in subtemperate regions where Equation (18) is appropriate, solution of the relevant boundary-value problem with the two thermal boundary conditions is necessary in order to determine the basal velocity. Finally, the base becomes actually temperate when $u$ reaches $F_{\mathrm{M}}(\tau)$. Then

$$
[-k \partial T / \partial y<G+\tau u] ; \quad u=F_{\mathrm{M}}(\tau), T=T_{\mathrm{M}} ;
$$

the heat-flux condition is no longer appropriate, because some of the heat flux is being used to melt basal ice. Lastly, Equation (19) is valid so long as $\partial T / \partial y<0$. If $\partial T / \partial y$ becomes equal to zero at the base, then a zone of temperate ice exists adjoining the base, and the ice is polythermal.

Computations involving polythermal ice have not been done, and perhaps are not needed. The important point that needs to be made here is that in many cases the full sliding law $F_{\mathrm{M}}(\tau)$ may be large, and then it is unlikely to be ever attained. Rather than jumping from Equation (17) to Equation (19), when the base becomes (nearly) temperate, the extra-thermal condition in Equation (18) determines the thickness and also the amount of sliding. In particular, it is likely that imposition of a sliding law for large ice sheets may be irrelevant, except insofar as this may represent an effective sliding due to large shear of highly strained basal ice (Nye, 1959).

To conclude:

(a) For a given stress, the sliding velocity depends continuously on temperature below the melting point $T_{\mathrm{M}}$;

(b) Inclusion of solid friction for $T<T_{\mathrm{M}}$ yields a sliding velocity which is (i) negligible (but non-zero) for $T<T_{\mathrm{M}}-\Delta T$, (ii) significant for $T_{\mathrm{M}}-\Delta T<T<T_{\mathrm{M}}$;

(c) Based on results of Barnes and others (1971), we find $\Delta T$ is given by Equation (14), and depends on the mean bedrock slope; for $\alpha=0.1$ (a $6^{\circ}$ slope), $\Delta T \sim 0.22$ deg. For a $10^{\circ}$ slope, $\alpha \sim 0.18, \Delta T \sim 0.7 \mathrm{deg}$, and for a $20^{8}$ slope, $\Delta T \sim 3 \mathrm{deg}$.

(d) The resultant motion will be of stick-slip type (and 
may be distinguished by this); it can reasonably explain recent observations of Echelmeyer and Hallet.

(e) Even if $\Delta T$ is very small (e.g. for ice sheets), there is nevertheless an extensive region in which "sub-temperate sliding" occurs. This is characterized by the existence of cold ice to bedrock, whose temperature reaches $T_{\mathrm{M}}$ at the bed. Instances are sub-polar glaciers and ice caps.

(f) In this region, the sliding velocity is controlled through the flow dynamics by prescription of an extrathermal boundary condition. There is no reason then to expect a functional relationship between stress and velocity. If the fully temperate sliding velocity is "large", such subtemperate sliding will prevail everywhere, at least in the steady state.

\section{ACKNOWLEDGEMENTS}

My thanks are due to $K$. Echelmeyer and B. Hallet for discussion.

\section{REFERENCES}

Barnes, P., and others. 1971. The friction and creep of polycrystalline ice, by P. Barnes, D. Tabor, and J.C.F Walker. Proceedings of the Royal Society of London, Ser. A, Vol. 324 , No. 1557 , p. 127-55.
Clarke, G.K.C., and others. 1984. Flow, thermal structure, and subglacial conditions of a surge-type glacier, by G.K.C. Clarke, S.G. Collins, and D.E. Thompson. Canadian Journal of Earth Sciences, Vol. 21, No. 2, p. $232-40$.

Fowler, A.C. 1979. The use of a rational model in the mathematical analysis of a polythermal glacier. Journal of Glaciology, Vol. 24, No. 90, p. 443-56.

Fowler, A.C. 1981. A theoretical treatment of the sliding of glaciers in the absence of cavitation. Philosophical Transactions of the Royal Society of London, Ser. A Vol. 298 , No. 1445 , p. $637-85$.

Fowler, A.C., and Larson, D.A. 1980. The uniqueness of steady state flows of glaciers and ice sheets. Geophysical Journal of the Royal Astronomical Society, Vol. 63, No. 2 , p. $333-45$.

Hutter, K. 1982. Dynamics of glaciers and large ice masses. Annual Review of Fluid Mechanics, Vol. 14, p. 87-130.

Hutter, K., and Olunloyo, V.O.S. 1980. On the distribution of stress and velocity in an ice strip, which is partly sliding over and partly adhering to its bed, by using a Newtonian viscous approximation. Proceedings of the Royal Society of London, Ser. A, Vol. 373, No. 1754, p. 385-403.

Hutter, K., and Olunloyo, V.O.S. 1981. Basal stress concentrations due to abrupt changes in boundary conditions: a cause for high till concentration at the bottom of a glacier. Annals of Glaciology, Vol. 2, p. 29-33.

Nye, J.F. 1959. The motion of ice sheets and glaciers. Journal of Glaciology, Vol. 3, No. 26, p. 493-507.

Shreve, R.L. 1984. Glacier sliding at subfreezing temperatures. Journal of Glaciology, Vol. 30, No. 106, p. $341-47$. 